\title{
Antibody delivery into viable epimastigotes of Trypanosoma cruzi as a tool to study the parasite biology
}

\author{
Karla Y. Acosta-Viana ${ }^{1 *}$, Huchin-Cetz Julio ${ }^{1}$, Jimenez-Coello Matilde ${ }^{1}$, Guzman-Marin Eugenia ${ }^{1}$, \\ Jose L. Rosales-Encina ${ }^{2}$ \\ ${ }^{1}$ Laboratorio Biologia Celular, Centro de Investigaciones Regionales "Dr. Hideyo Noguchi”, Universidad Autonoma de Yucatan, \\ Merida, Mexico \\ ${ }^{2}$ Departamento de Infectomica y Patogenesis Molecular, Centro de Investigación y de Estudios Avanzados del Instituto Politecnico \\ Nacional, Unidad Zacatenco, México \\ Email: ${ }^{*}$ aviana@uady.mx
}

Received 12 March 2013; revised 2 May 2013; accepted 17 May 2013

Copyright (C) 2013 Karla Y. Acosta-Viana et al. This is an open access article distributed under the Creative Commons Attribution License, which permits unrestricted use, distribution, and reproduction in any medium, provided the original work is properly cited.

\begin{abstract}
American trypanosomiasis is a zoonosis of worldwide medical importance and currently there is no effective treatment in chronic patients, hence the importance of the study of protein function of the parasite with the objective of finding new drug targets and to know better the biology of the agent causal (Trypanosoma cruzi). T. cruzi is an RNAi-negative parasite, therefore the silencing genes strategies by RNAi is not possible; for that reason, antibodies may be taken as a tool for studying the parasite proteins function by blocking these molecules with specific antibodies. The aim of this work was to establish a methodology for antibody delivery (antibody transfection) into viable parasites. We used anti-cyclin-A antibody (human origin) in western blot assay with epimastigote of $T$. cruzi proteins and this recognized a $\sim 55 \mathrm{kDa}$ polypeptide. Several methods for antibody transfection (electroporation, saponin permeabilization and a lipid-based formulation) were tested. The first two methods were unsuccessful. In electroporation was impossible to visualize the antibody inside parasites and with saponin permeabilization, antibodies were successfully introduced, but with loss of parasites viability. The lipid-based formulation method forms noncovalent complexes with antibodies. These complexes are internalized by cells and antibodies are released into the cytoplasm. With this method, a successful antibody delivery was achieved. Anti-cyclin antibodies were visualized in the cytoplasm from fixed transfected parasites (immunofluorescence assays). At $24 \mathrm{~h}$ post-transfection, parasites maintained their viability $(90 \%)$ and were able to arrest the cell cycle in G0/G1-

*Corresponding author.
\end{abstract}

phase of cultured epimastigotes (cell population in creased in G0/G1-phase from $50.5 \%$ to $66.2 \%$ and decreased in S-phase from $47.2 \%$ to $26 \%$ ). It was also observed that anti-cyclin-A antibodies inhibit the parasite population doubling $(\mathrm{p}<0.05,95 \% \mathrm{CI})$. This is the first report of antibody-delivery into viable epimastigote forms of $T$. cruzi, with a simple and cheap technique, which will allows carrying out further studies of this protozoan.

Keywords: Trypanosoma cruzi; Antibody Delivery; Antibody Transfection; Cell Cycle;

Anti-Cyclin-A Antibody

\section{INTRODUCTION}

Chagas disease or American tripanosomiasis, is a zoonosis ranked as one the seventeen neglected tropical diseases in the world [1]. It is caused by the protozoan parasite Trypanosoma cruzi (T. cruzi) whose principal route of transmission to human is by feces of infected triatomine bugs. In fact sheet no. 340 of the World Health Organization (WHO) estimates that 10 million people are infected with T. cruzi worldwide, mainly in Latin America and more than 25 million people are at risk of infection [2]. After more than 100 years of the discovery of Chagas disease, there is not any effective treatment available and the drugs used are lightly effective only during the early infection $[3,4]$. This scenario requires the continuous search for strategies to eradicate this disease, including treatment, control and prevention. Therefore, it is relevant the searching for new alternative treatments, identify new pharmacological targets and a better knowledge of the parasite biology.

The complete sequencing of trypanosomatids genomes 
represented a breakthrough for the understanding of these organisms. Genome sequencing is a step towards knowing the parasite biology, as there are a large percentage of genes with open reading frames of which function is still unknown. Genes are commonly transfected into parasites to demonstrate: protein sub-cellular localization [5], identification of protein interactions [6], protein overexpression [7], gene knockout [8,9], gene silencing [10] within others.

The great discovery that double stranded RNA (dsRNA) triggers downregulation of gene expression, a process known as RNA interference (RNAi) [11] has facilitated the analysis of gene function and therefore the proteins encoded by these. First protozoan that showed this silencing route was Trypanosoma brucei [12], unfortunately, T. cruzi does not have all the components for this silencing pathway (RNAi-negative parasite) $[10,13,14]$.

On the other hand, antibodies give us the chance to know the events taking place in living cells. For several decades, it has been reported the introduction of proteinaceous molecules in mammals cells by different methods $[15,16]$. Some of these studies reported the electroporation as a technique for antibody delivery inside mammalian cells. Chakrabarti et al. (1989), described a method for introduction of monoclonal anti- bodies (Mab 3F3 y Mab2B4) in HeLa, HT-5 and L5178YD10/R cells to study metabolic processes in this kind of cells and reported that $80 \%-90 \%$ of electropermeabilized cells were viable [17]. Also, it has been reported antibody transfection inside B16BL6 mouse melanoma cells, where antibodies against $\mathrm{p} 21$ ras protein (encoded by ras oncogenes) were introduced; the authors suggested that electroporation of the cells should be in the presence of the antibody [18,19]. Bright et al. (1996) conducted a study in where smooth and skeletal muscle cell lines and primary bovine and rat aortic smooth muscle cells were tested. Results of this study indicated that electroporation of the cells was most efficient in adherent cells than in resuspended cells because receptors and other membrane proteins were not cleaved by proteases that are used to release cells in a liquid media for electroporation [15].

Detergents such as saponin and digitonin are commonly used for permeabilization of cell membranes for different purposes. Permeabilization of cells with saponin to release cytosolic components is a widely used technique in different cell systems [20]. A method for the introduction of antibodies by plasmatic membrane permeabilization with detergents has been reported. Plasmatic membranes of rat hepatocytes in culture were permeabilized with saponin at $0.04 \mathrm{mg} / \mathrm{mL}$, under these conditions the cytoplasmic contents were released [21]. It has also been reported the cardiac myocytes permeabilization with $50 \mu \mathrm{g} / \mathrm{mL}$ saponin to introduce peptides into these cells, these results indicated the integrity of the plasmatic membranes were not compromised, but only $10 \%$ of the antibodies were introduced. This procedure involves saponin permeabilization of the cells on ice in the presence of ATP and caused minimal effects on neonatal cardiac myocytes physiology and cell survival [22]. When cardiomyocytes were permeabilized with $0.01 \%$ saponin, cytoplasm components were released in small quantities [23]. CHO and HFF cells have been used to study the Toxoplasma gondii parasitophorous vacuole membrane (PVM) by digitonin permeabilization. Digitonin concentrations in the range of $0.001 \%-0.005 \%$ usually showed good plasma membrane permeabillization without affecting the PVM [24]. Also it has been reported digitonin permeabilization of mammalian and plant cells in studies of viral proteins. In HeLa and human Colo-205 cells digitonin permeabilized were introduced synthetic peptides of proteins of bean dwarf mosaic virus (BDMV), tomato yellow leaf curl virus (TYLCV) and virus and human immumodeficiency virus type 1 (HIV-1); these synthetic peptides contained putative nuclear localization signals of karyophilic proteins (capsid protein and nuclear shuttle protein for BDMV and TYLCV) [25] and the human immunodeficiency virus type 1 (HIV-1) matrix protein (HIV-MA) [26] and integrase protein (HIV-IN) [27]. Other methods for protein delivery in mammal cells have been reported. Todorova (2008), made a review of these techniques which included osmotic lysisis of pinocytic vesicles, electroporation, microinjection, cell penetrating peptide TAT, lipid-based delivery system, non-covalent complex formation, cationic liposomes, among others [28].

For introduction of protein molecules into cells, an important issue is the preservation of the antibody integrity and function, and to maintain stability of the plasma membrane. In neuronal cells has been reported the antibody delivery inside living cells using a lipid-based formulation (Ab-DeliverINTM, OZ Biosciences); in that report were transfected labeled antibodies into living neurons with an efficiency above 55\% without altering the antibody functionality and cell viability [16].

Because T. cruzi is an RNAi-negative-parasite, it is not possible implementing RNAi strategies. Therefore the delivery of antibodies inside living cells represents an alternative to nucleic acids transfection; it is also a cheap, easy and powerful strategy for functional studies or therapeutic approaches. The main objective of this study was to develop a technique for transfection of functional antibodies into viable epimastigotes of $T$. cruzi, so that it could be used in studies of protein function, pharmacological targets search and in general for a better understanding of the biology of this parasite. We used a lipidbased formulation which forms non-covalent complexes 
with antibodies. Complexes are internalized by cells and antibodies are released into the cytoplasm without any cytotoxicity. In order to evaluate the technique, polyclonal anti-cyclin-A of human origin were used and with them, we evaluated the effect of delivery antibodies on cell cycle of $T$. cruzi epimastigote forms.

\section{MATERIAL AND METHODS}

\subsection{Parasites}

Epimastigotes forms of the T. cruzi Y strain were grown in liver infusion tryptose broth (LIT) supplemented with $10 \%$ fetal bovine serum (FBS) (GIBCO Life Technologies Corporation) at $28^{\circ} \mathrm{C}$ [29]. All the experiments were carried out with parasites cultures at the exponential phase of growth.

\subsection{Antibodies}

In western blot, antibody delivery and immunofluorescence assays, were used anti-cyclin-A antibody (rabbit polyclonal IgG of human origin, Santa Cruz Biotechnology, Inc., cat. \# H-432, sc-751). Secondary antibodies goat anti-rabbit $\mathrm{IgG}$ conjugated to alkaline phosphatase (AP) (Santa Cruz Biotechnology, Inc. cat. \# sc-2007) were used in western blot assays and goat anti-rabbit IgG immunoglobulin labeled with fluorescein isothiocyanate (FITC) (Santa Cruz Biotechnology, Inc., cat. \# sc-2012) in immunofluorescence assays. As antibody-transfection control, was used an anti-IgG-FITC provided by OZ Biosciences.

\subsection{Western Blotting}

Briefly, crude antigen extracts of T. cruzi (Y strain) were separated by electrophoresis in a 10\% SDS-PAGE [30] and electroblotted onto a nitrocellulose membrane (Merck Millipore) [31]. Nonspecific binding sites were blocked with $1 \%$ solution of nonfat milk powder in TBST buffer (50 mM Tris- $\mathrm{HCl} \mathrm{pH} 7.4,150 \mathrm{mM} \mathrm{NaCl}$, $0.05 \%$ Tween 20 ). The membranes were probed with 1:5000 cyclin-A antibody solution in TBST-milk and detected with 1:5000 dilution of a secondary antibody conjugated to alkaline-phosphatase. Immunocomplex were developed with NBT (nitro-blue-tetrazolium) and BCIP (5-bromo-4-chloro-3-indolylphosphate) (Bio-Rad, cat. num. 170-6432). Secondary antibody control was included.

\subsection{Antibody Delivery into Viable Parasites}

There were tested three different antibody transfection techniques: electroporation, saponin permeabilization and using Ab-DeliveIN ${ }^{\mathrm{TM}}$ reagent.

Electroporation. Harvested $1 \times 10^{8}$ epimastigotes, washed once at room temperature (RT) in phosphate buffer saline (PBS, pH 7.0) and resuspended in $400 \mu \mathrm{L}$ of electroporation buffer (PBS pH 7.0, $0.5 \mathrm{mM}$ magnesium acetate, $0.1 \mathrm{mM} \mathrm{CaCl}{ }_{2}$ ) containing the anti-cyclin- $\mathrm{A}$ antibody at a final dilution 1:40. Cells/anti-cyclin-A mix was dispensed into disposable 0.2-mm gap cuvettes (BioRad, Cat Num 165-2089). Initially, parasites were electroporated by using a Bio-Rad Gene Pulser (Cat Num $165-2660)$ set at $300 \mathrm{~V}$ and $500 \mu \mathrm{F}$ with four pulses in close succession ( $1 \mathrm{~s}$ between pulses). Samples were placed on ice for $10 \mathrm{~min}$ and then were transferred to a flask containing $5 \mathrm{~mL}$ of supplemented LIT medium, 100 $\mathrm{U} / \mathrm{mL}$ penicillin and $100 \mu \mathrm{g} / \mathrm{mL}$ streptomycin [32]. The epimastigotes were incubated at $28^{\circ} \mathrm{C}$ during $24 \mathrm{~h}$ and subsequently antibody transfection was evaluated by immunofluorescence assays (IFA). As a positive control anti-IgG-FITC transfected parasites were used and as a negative control electroporated parasites without antibodies.

Saponin permeabilization. Methods described for protozoa permeabilization with digitonin [33] and saponin were used [34,35]. Harvested $7 \times 10^{6}$ epimastigotes and then were resuspended in $957.75 \mu \mathrm{L}$ of supplemented LIT medium. Subsequently $31.25 \mu \mathrm{L}$ of anti-cyclin-A antibodies (1:32) and $11 \mu \mathrm{L}$ of $0.1 \%$ of saponin were added, then incubated at RT during 20 min, parasites were then harvested and resuspended in LIT medium with anti-cyclin-A antibodies a final dilution 1:32, incubated $30 \mathrm{~min}$ at RT. Saponin permeabilized parasites plus anti-IgG-FITC were used as a positive control and saponin permeabilized parasites without antibodies were considered negative control. Antibody transfection was evaluated with IFA.

$A b$-DeliverIN ${ }^{\mathrm{TM}}$. In the third method Ab-DeliverIN ${ }^{\mathrm{TM}}$ reagent (OZ Biosciences) was used, which is a lipid formulation capable to form non-covalent complexes with antibodies through non-covalent electrostatic and hydrophobic interactions and delivering them inside cells [16]. For antibody transfection assay BSA free polyclonal anti-cyclin-A was used. First, the antibody solution to be delivered was prepared in PBS at $100 \mu \mathrm{g} / \mathrm{mL}$. Moreover, were taken $0.4 \mu \mathrm{L}$ of $\mathrm{Ab}$-DeliverIN ${ }^{\mathrm{TM}}$ reagent and placed in one microtube, immediately was added 0.4 $\mu \mathrm{g}$ of antibody previously diluted, was mixed by pipetting up and down several times and incubated at RT for 15 min. Subsequently, was added serum-free LIT medium for a total volume of $20 \mu \mathrm{L}$. The mixture of Ab-DeliverIN ${ }^{\mathrm{TM}} /$ anti-cyclin-A antibodies was deposited in a 96 well plate containing $1 \times 10^{6}$ parasites in $100 \mu \mathrm{L}$ of LIT medium with $10 \%$ FBS. The parasites were incubated at $28^{\circ} \mathrm{C}$, for $24 \mathrm{~h}$, then parasites were counted in a Neubauer chamber and viability was measured by trypan blue exclusion method. Antibody transfection was evaluated for IFA and its effect on parasite DNA synthesis for flow cytometry. As a negative control epimastigotes 
treated only with the Ab-DeliverIN ${ }^{\mathrm{TM}}$ reagent were used and parasites transfected with $0.4 \mu \mathrm{g}$ of FITC-labeled IgG (included by OZ Biosciences) were used as a positive control. Assays were performed three times, each with five replicates.

\subsection{Immunofluorescence Assays}

Were harvested $1 \times 10^{5}$ antibody transfected parasites (anti-cyclin-A), were washed and resuspended in $10 \mu \mathrm{L}$ of PBS, pH 7.4 and then were seeded on poly-L-lysine coated slides (Thermo Fisher Scientific Inc.). Parasites fixed and permeabilized with methanol at $20^{\circ} \mathrm{C}, 30 \mathrm{~min}$. were blocked with $50 \%$ horse serum in PBS at RT. For transfected antibodies detection, anti-IgG-FITC (1:80) and $0.01 \%$ Evan's blue were used. The parasites were observed under an epifluorescence microscope (Nikon Instruments Inc.). As a negative control, parasites treated with $\mathrm{Ab}$-DeliverIN ${ }^{\mathrm{TM}}$ reagent (without antibodies) were used. As a positive control, antibody transfected parasites with FITC-labeled IgG were used.

\subsection{Flow Cytometry}

For cell DNA content analysis antibody transfected cells, $5 \times 10^{6}$ antibody transfected and untransfected epimastigotes were collected by low speed centrifugation and washed with PBS and then fixed with $70 \%$ ethanol during $2 \mathrm{~h}$ at $4^{\circ} \mathrm{C}$. Subsequently, parasites were harvested and the pellet was washed with PBS and resuspended in RNase buffer $(10 \mu \mathrm{g} / \mathrm{mL}$ RNase A in PBS) for incubation during for $20 \mathrm{~min}$ at $37^{\circ} \mathrm{C}$. For fluorescence-activated cell sorting (FACS) analysis, cells were stained with propidium iodide in PBS at final concentration of $20 \mu \mathrm{g} / \mathrm{mL}$, [36,37]. $15 \mathrm{~min}$ at $4^{\circ} \mathrm{C}$ followed by cell sorting analysis in a flow cytometer FACScalibur (Becton-Dickinson) using CELLQuest software (BD Biosciences). The acquired FACS data were analyzed by ModFit LT software (Verity Software House, Inc.).

\subsection{Statistical Analysis}

Data were presented as mean \pm SD (standard deviation) and were analyzed using t-student test. The statistics software package IBM SPSS Statistics 20.0 was used to perform the calculations. If $p<0.05$, then the result was judged to be significant.

\section{RESULTS AND DISCUSSION}

The main objective of this study was to find a good method and optimal conditions for delivery antibodies into viable epimastigotes of $T$. cruzi, in order to have a simple tool for studying the parasite biology, particularly for protein function tests or the study and validation of potential therapeutic targets. In this study the anti-cy-
clin-A antibody were used in FACS assays to evaluate the effect of the transfected antibodies over the parasite DNA synthesis.

\subsection{Anti-Cyclin-A Antibodies of Human Origin Recognize a T. cruzi Polypeptide}

Prior to transfection assays, anti-cyclin-A antibodies were tested in western blot assays onto total protein extracts of T. cruzi epimastigotes and it was observed that anti-cyclin-A antibodies of human origin recognizing an approximately $55 \mathrm{kDa}$ polypeptide (Figure 1).

\subsection{Antibody Delivery to the Cytoplasm of Viable Epimastigotes.}

Electroporation. For antibodies transfection by electroporation, there were used tested conditions previously described for transfection of plasmids into T. cruzi [32], under these conditions parasites remains viable, but antibodies were not displayed in the interior of parasites. Variations in the number of pulses (up to 10 successive pulses) and voltage (up to $400 \mathrm{~V}$ ) were also made, but not

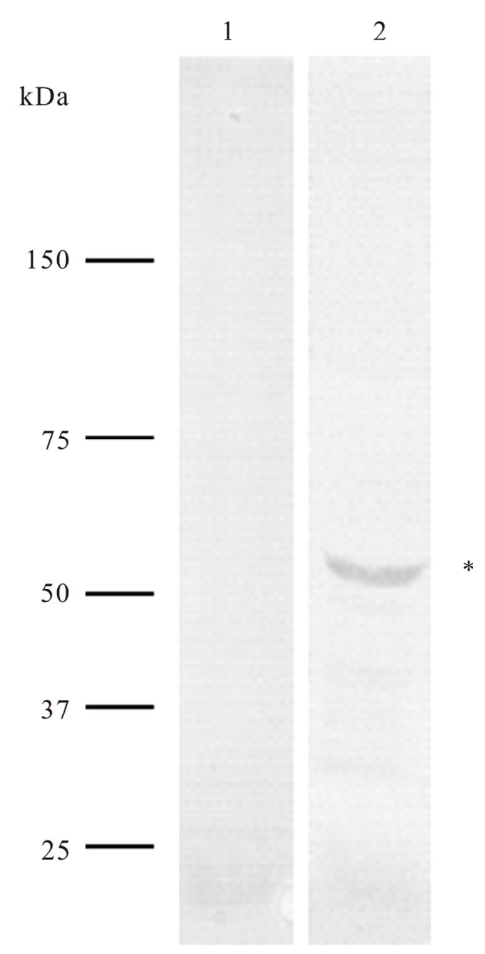

Figure 1. Western blot analysis of Trypanosoma cruzi total proteins (epimastigote forms) using anti-cyclin-A antibody of human origin (lane 2). These antibodies recognize a $\sim 55$ $\mathrm{kDa}$ polypeptide). As a negative control, only the secondary antibodies (anti-IgG-alkaline phosphatase) were used (lane 1). 
satisfactory results were obtained (data not shown). There are studies in which electroporation has been reported as a method for introducing peptides, enzymes, antibodies among other proteic nature molecules, but have been performed in cultured mammalian cells [18, 19,28]. For example, monoclonal antibodies were introduced into HeLa cells with a single brief electric pulse of $750 \mathrm{~V}$ and duration of $0.7-0.9 \mathrm{~ms}$ at RT. [17] Also has been reported an antibody-transfection protocol in B16BL6 mouse melanoma cells, wherein the anti-RAS p21 antibodies were transfected by a single pulse at $275 \mathrm{~V}$ and they observed that the antibody enters at the cells without losing their viability [19]. Several cell lines (SW 3T3, NIH 3T3, A7r5 smooth muscle, PC-12 and L6 skeletal muscle) and primary cultures of tissues (bovine and rat aortic smooth muscle) were used to find the optimal conditions of electroporation to introduce antibodies into viable adherent mammalian cells [15]. Bright demonstrate the importance of parameters such as voltage, capacitance, electrical pulses number and duration of these, electroporation buffer, composition and even the cell kind. They reported that the optimal conditions are $300 \mathrm{~V}$, $540 \mu \mathrm{F}$, with three pulses spaced $10 \mathrm{~s}$ apart and lowionic-strength electroporation buffer. In the present study the conditions were similar, $300-400 \mathrm{~V}, 500 \mu \mathrm{F}$, with four successive pulses ( $1 \mathrm{~s}$ between pulses), electroporation buffer of low ionic strength. Is possible that the membrane composition of this parasite has influenced the results or maybe the time it remains unstable the membrane (pore formation) was very short [28].

Saponin permeabilization. In present study the concentration of saponin to which the parasites remain mobile was $10 \mu \mathrm{g} / \mathrm{mL}$. However, in the literature have been reported concentrations above this to permeabilize the plasmatic membrane of different cell types [21-23], but in epimastigotes of $T$. cruzi, when concentrations where above $10 \mu \mathrm{g} / \mathrm{mL}$ lysisis was induced (data not shown). Saponin permeabilized parasites, antibody transfected, were analyzed by IFA and antibodies into cytoplasm of the parasite were observed. However, after $24 \mathrm{~h}$, the parasites had lost their shape and mobility (data not shown).

Ab-DeliverIN ${ }^{\mathrm{TM}}$ transfection. Since not satisfactory results in antibody transfection were obtained with previously described methods, the Ab-DeliverIN'M transfection method was used. First a transfection antibody control (IgG-FITC, provided by OZ, Biosciences) was tested. After antibody transfection, samples were taken at 3,6, 16 y $24 \mathrm{~h}$, fixed and analyzed by IFA. As of $3 \mathrm{~h}$, antibodies were visualized into transfected parasite cytoplasm (Figure 2(b)). Subsequently, when epimastigotes were transfected with anti-cyclin-A antibodies a punctual distribution into cytoplasm of fixed parasites was observed (Figure 2(c)). Besides when antibodies were suc-
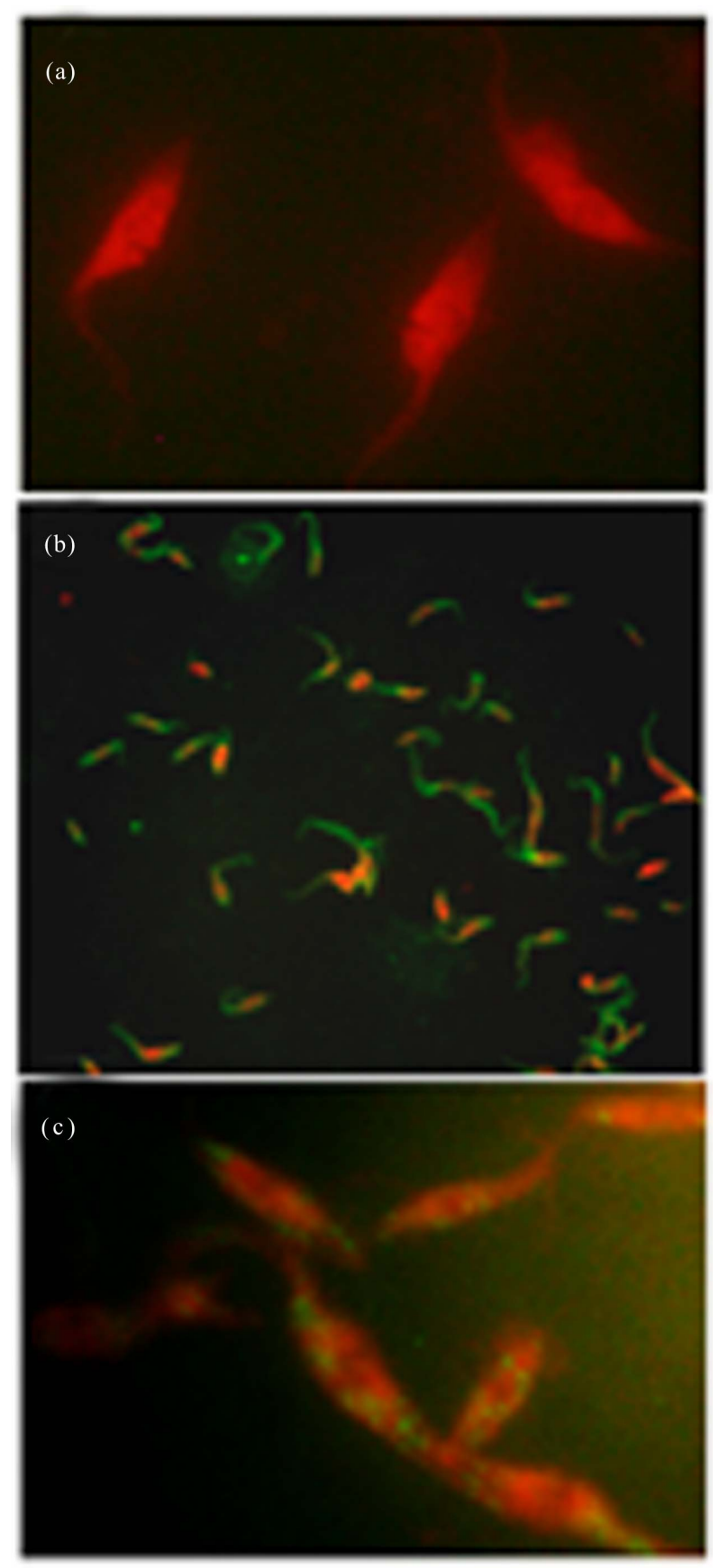

Figure 2. Immunolocalization of anti-cyclin-A antibodies in transfected Trypanosoma cruzi epimastigotes forms using AbDeliverINTM . (a) Negative control (parasites + Ab-DeliverIN ${ }^{\mathrm{TM}}$, $100 \times$ ), (b) positive control (Ab-DeliverINTM + FITC-labeled IgG, 40×) and (c) anti-cyclin-A antibody transfected parasites.

cessfully delivered into cells, it was observed that the anti-cyclin-A/Ab-DeliverINTM complex where not cytotoxic, since after $24 \mathrm{~h}$ of incubation with the delivery complex, epimastigotes were observed with normal morphology and mobile. Viability was measured by the trypan blue exclusion method and we found that before transfection, $92 \%$ of the parasites were viable and after 
anti-cyclin-A antibody transfection, 90\%. There are numerous reports of successful intracellular protein delivery using cationic lipids, $\mathrm{pH}$-responsive liposomes and lipid-based delivery reagent; however, these reports have been done in mammalian cells [38], as an example, Douglas et al. (2012) reported the successful antibody transfection into living neurons with Ab-DeliverIN reagent. They found a transfection efficiency of more than $55 \%$. The ability to transfect living cells could be used to test hypothesis related directly to the interaction between the antibody of interest and its intracellular target [16].

\subsection{Effect of Anti-Cyclin-A Antibodies in Cell Cycle of Epimastigotes of T. cruzi.}

For the epimastigotes form, FACS analysis of the cell population by their DNA content indicated that after anti-cyclin-A antibody transfection $(24 \mathrm{~h})$, cells in the G0/G1-phase were increased from approximately 50.5\% to $66.2 \%$ of the population. The S-phase cells were reduced from $47.2 \%$ to $26.8 \%$ and the G2/M-phase cells showed a slight increase from $2.3 \%$ to $7.0 \%$. (Figures 3(a) and (b)). These results suggest the cell cycle arrest in G0/G1-phase, since we observed an accumulation of the population in this phase, and a decrease in S-phase population. Moreover, at the time of transfection, were taken $1 \times 10^{6}$ parasites $/ \mathrm{mL}$ (including negative control, Ab-DeliverINTM only), and $24 \mathrm{~h}$ post-antibody transfection there were compared the number of parasites $/ \mathrm{mL}$ and it was observed an average of $1.61 \times 10^{6}$ parasites/ $\mathrm{mL}\left(\mathrm{SD} \pm 0.12 \times 10^{6}\right)$ in anti-cyclin-A antibody transfected cultures and $1.98 \times 10^{6}$ parasites $/ \mathrm{mL}(\mathrm{SD} \pm 0.19 \times$ $10^{6}$ ) in control cultures. These data suggest that anticyclin-A antibodies inhibit the parasite population doubling ( $p<0.05,95 \% \mathrm{CI})$. Although the aim of this study is focused on the antibody transfection method in viable parasites, we can observe the effect of anti-cyclin-A antibodies (human origin) in the cell cycle of epimastigote form of T. cruzi. Few cyclin proteins have been described in $T$. cruzi $[39,40]$, however, there is only one of them reported as a functional cyclin ( $\mathrm{TcCYC} 2)$, [41] therefore we would have to confirm the protean nature of the molecular target (in T. cruzi) of anti-cyclin-A antibody (human origin). This work is the first report of antibody transfection method in trypanosomatids, particularly $T$. cruzi. As it is well known, T. cruzi lacks the machinery for gene silencing by RNA interference [9], therefore this method is an excellent tool for the characterization of therapeutic targets, the study of protein function and therefore for a better understanding of the biology of these parasites.

\section{CONCLUSION}

First of all, we standardize an antibody transfection tech-
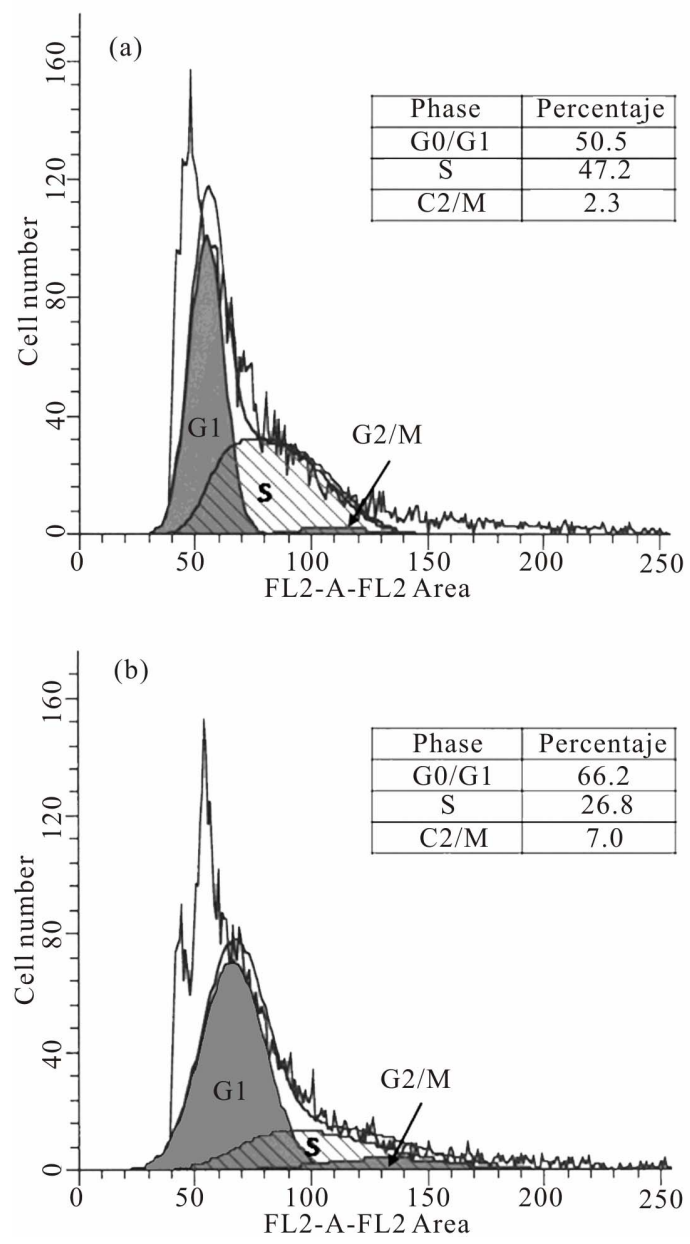

Figure 3. Effect of the cyclin-A antibodies in cell cycle of T. cruzi epimastigote forms. For fluorescence-activated cell sorting (FACS) analysis, both anti-cyclin-Aantibody transfected (b) and nontransfected epimastigotes (a) were stained with a mixture of propidium iodide buffer followed by cell sorting analysis. The acquired FACS data were analyzed by ModFit LT V3.1 software (Verity Software House, Inc.).

nique into viable epimastigotes of Trypanosoma cruzi using a lipid-based formulation (Ab-DeliverIN ${ }^{\mathrm{TM}}$ ), preserving the structure and function of the transfected antibody and maintaining the cellular viability. In second place, we determined that anti-cyclin-A antibody of human origin recognize in total protein extracts of $T$. cruzi a $55 \mathrm{kDa}$ polypeptide. These antibodies, when delivered into viable epimastigote forms of $T$. cruzi, have the capacity to arrest the cell cycle in G0/G1-phase, plus they have effect on parasite population doubling. However, we must determine the nature of the protein-target for anti-cyclin-A antibody of human origin. Finally, this is the first report of antibody-delivery into viable epimastigote forms of $T$. cruzi, with a simple and cheap technique, which will allow us carry out studies in this protozoan. 


\section{ACKNOWLEDGEMENTS}

This work was supported by the National Council of Science and Technology (CONACyT), Mexico. I0003-Fondo SEP-CONACYT (research grant no. 000000000083948).

\section{REFERENCES}

[1] World Health Organization (2013) http://www.who.int/neglected_diseases/diseases/en/

[2] World Health Organization (2012) http://www.who.int/mediacentre/factsheets/fs340/en/inde x.html

[3] Cancado, J.R. (2002) Long term evaluation of etiological treatment of chagas disease with benznidazole. Revista do Instituto de Medicina Tropical de Sao Paulo, 44, 29-37. doi:10.1590/S0036-46652002000100006

[4] Guedes, P.M., Silva, G.K., Gutierrez, F.R. and Silva, J.S. (2011) Current status of Chagas disease chemotherapy. Expert Review of Anti-Infective Therapy, 9, 609-620. doi:10.1586/eri.11.31

[5] Tetaud, E., Lecuix, I., Sheldrake, T., Baltz, T. and Fairlamb, A.H. (2002) A new expression vector for Crithidia fasciculata and Leishmania. Molecular and Biochemical Parasitology, 120, 195-204. doi:10.1016/S0166-6851(02)00002-6

[6] Schimanski, B., Nguyen, T.N. and Gunzl, A. (2005) Highly efficient tandem affinity purification of trypanosome protein complexes based on a novel epitope combination. Eukaryotic Cell, 4, 1942-1950. doi:10.1128/EC.4.11.1942-1950.2005

[7] Martinez-Calvillo, S., Lopez, I. and Hernandez, R. (1997) pRIBOTEX expression vector: A pTEX derivative for a rapid selection of Trypanosoma cruzi transfectants. Gene, 199, 71-76. doi:10.1016/S0378-1119(97)00348-X

[8] Xu, D., Brandan, C.P., Basombrio, M.A. and Tarleton, R.L. (2009) Evaluation of high efficiency gene knockout strategies for Trypanosoma cruzi. BMC Microbiology, 9, 90. doi:10.1186/1471-2180-9-90

[9] Taylor, M.C., Huang, H. and Kelly, J.M. (2011) Advances in Parasitology. Academic Press, Waltham.

[10] Wirtz, E., Leal, S., Ochatt, C. and Cross, G.A. (1999) A tightly regulated inducible expression system for conditional gene knock-outs and dominant-negative genetics in Trypanosoma brucei. Molecular and Biochemical Parasitology, 99, 89-101. doi:10.1016/S0166-6851(99)00002-X

[11] Fire, A., Xu, S., Montgomery, M.K., Kostas, S.A., Driver, S.E. and Mello, C.C. (1998) Potent and specific genetic interference by double-stranded RNA in Caenorhabditis elegans. Nature, 391, 806-811. doi:10.1038/35888

[12] Kolev, N.G., Tschudi, C. and Ullu, E. (2011) RNA interference in protozoan parasites: achievements and challenges. Eukaryotic Cell, 10, 1156-1163. doi:10.1128/EC.05114-11

[13] DaRocha, W.D., Otsu, K., Teixeira, S.M. and Donelson, J.E. (2004) Tests of cytoplasmic RNA interference (RNAi) and construction of a tetracycline-inducible T7 promoter system in Trypanosoma cruzi. Molecular and Biochemi- cal Parasitology, 133, 175-186.

doi:10.1016/j.molbiopara.2003.10.005

[14] Barnes, R.L., Shi, H., Kolev, N.G., Tschudi, C. and Ullu, E. (2012) Comparative Genomics Reveals Two Novel RNAi Factors in Trypanosoma brucei and Provides Insight into the Core Machinery. PLoS Pathogens, 8, e1002678. doi:10.1371/journal.ppat.1002678

[15] Bright, G.R., Kuo, N.-T., Chow, D., Burden, S., Dowe, C. and Przybylski, R.J. (1996) Delivery of macromolecules into adherent cells via electroporation for use in fluorescence spectroscopic imaging and metabolic studies. $C y$ tometry, 24, 226-233.

doi:10.1002/(SICI)1097-0320(19960701)24:3<226::AIDCYTO5>3.3.CO;2-Y

[16] Douglas, J.N., Gardner, L.A., Lee, S., Shin, Y., Groover, C.J. and Levin, M.C. (2012) Antibody transfection into neurons as a tool to study disease pathogenesis. Journal of Visualized Experiments, 67, e4154.

[17] Chakrabarti, R., Wylie, D.E. and Schuster, S.M. (1989) Transfer of monoclonal antibodies into mammalian cells by electroporation. Journal of Biological Chemistry, 264, 15494-15500.

[18] Berglund, D.L. and Starkey, J.R. (1989) Isolation of viable tumor cells following introduction of labelled antibody to an intracellular oncogene product using electroporation. Journal of Immunological Methods, 125, 79-87. doi:10.1016/0022-1759(89)90080-X

[19] Berglund, D.L. and Starkey, J.R. (1991) Introduction of antibody into viable cells using electroporation. Cytometry, 12, 64-67. doi:10.1002/cyto.990120109

[20] Wilcox, R.A. (1999) Methods in molecular biology. Humana Press Inc., Totowa.

[21] Wassler, M., Jonasson, I., Persson, R. and Fries, E. (1987) Differential permeabilization of membranes by saponin treatment of isolated rat hepatocytes. Release of secretory proteins. Biochemical Journal, 247, 407-415.

[22] Johnson, J.A., Gray, M.O., Karliner, J.S., Chen, C.H. and Mochly-Rosen, D. (1996) An improved permeabilization protocol for the introduction of peptides into cardiac myocytes. Application to protein kinase $\mathrm{C}$ research. Circulation Research, 79, 1086-1099. doi:10.1161/01.RES.79.6.1086

[23] Swift, L.M. and Sarvazyan, N. (2000) Localization of dichlorofluorescin in cardiac myocytes: Implications for assessment of oxidative stress. American Journal of Physiology-Heart and Circulatory Physiology, 278, H982H990.

[24] Beckers, C.J., Dubremetz, J.F., Mercereau-Puijalon, O. and Joiner, K.A. (1994) The toxoplasma gondii rhoptry protein ROP 2 is inserted into the parasitophorous vacuole membrane, surrounding the intracellular parasite, and is exposed to the host cell cytoplasm. The Journal of Cell Biology, 127, 947-961. doi:10.1083/jcb.127.4.947

[25] Kass, G., Arad, G., Rosenbluh, J., Gafni, Y., Graessmann, A., Rojas, M.R., Gilbertson, R.L. and Loyter, A. (2006) Permeabilized mammalian cells as an experimental system for nuclear import of geminiviral karyophilic proteins and of synthetic peptides derived from their nuclear localization signal regions. Journal of General Virology, 87, 2709-2720. doi:10.1099/vir.0.82021-0 
[26] Friedler, A., Zakai, N., Karni, O., Broder, Y.C., Baraz, L., Kotler, M., Loyter, A. and Gilon, C. (1998) Backbone cyclic peptide, which mimics the nuclear localization signal of human immunodeficiency virus type 1 matrix protein, inhibits nuclear import and virus production in nondividing cells. Biochemistry, 37, 5616-5622. doi:10.1021/bi972878h

[27] Armon-Omer, A., Graessmann, A. and Loyter, A. (2004) A synthetic peptide bearing the HIV-1 integrase 161 173 amino acid residues mediates active nuclear import and binding to importin $\alpha$ : Characterization of a functional nuclear localization signal. Journal of Molecular Biology, 336, 1117-1128. doi:10.1016/j.jmb.2003.11.057

[28] Todorova, R. (2008) Methods of protein delivery into mammalian cells for gene therapy and genetic studies. Acta Medica Bulgarica, 35, 3-11.

[29] Camargo, E.P. (1964) Growth and differentiation in Trypanosoma cruzi. Origin of metacyclic trypanosomes in liquid media. Revista do Instituto de Medicina Tropical de Sao Paulo, 6, 93-100.

[30] Laemmli, U.K. (1970) Cleavage of structural proteins during the assembly of the head of bacteriophage T4. Nature, 227, 680-685. doi:10.1038/227680a0

[31] Towbin, H., Staehelin, T. and Gordon, J. (1979) Electrophoretic transfer of proteins from polyacrylamide gels to nitrocellulose sheets: procedure and some applications. Proceedings of the National Academy of Sciences, 76, 4350-4354.

[32] Norris, K.A. (1998) Stable transfection of Trypanosoma cruzi epimastigotes with the trypomastigote-specific complement regulatory protein cDNA confers complement resistance. Infection and Immununity, 66, 2460-2465.

[33] Vercesi, A.E., Bernardes, C.F., Hoffmann, M.E., Gadelha, F.R. and Docampo, R. (1991) Digitonin permeabilization does not affect mitochondrial function and allows the determination of the mitochondrial membrane potential of Trypanosoma cruzi in Situ. The Journal of Biological Chemistry, 266, 14431-14434.

[34] Kawase, O., Nishikawa, Y., Bannai, H., Igarashi, M., Matsuo, T. and Xuan, X. (2010) Characterization of a novel thrombospondin-related protein in Toxoplasma gondii. Parasitology International, 59, 211-216. doi:10.1016/j.parint.2010.02.001

[35] Guinet, F., Louise, A., Jouin, H., Antoine, J.-C. and Roth, C.W. (2000) Accurate quantitation of Leishmania infection in cultured cells by flow cytometry. Cytometry, 39, 235-240.

doi:10.1002/(SICI) 1097-0320(20000301)39:3<235::AIDCYTO10>3.3.CO;2-C

[36] Tu, X. and Wang, C.C. (2005) Pairwise knockdowns of cdc2-related kinases (CRKs) in Trypanosoma brucei identified the CRKs for G1/S and G2/M transitions and demonstrated distinctive cytokinetic regulations between two developmental stages of the organism. Eukaryotic Cell, 4, 755-764. doi:10.1128/EC.4.4.755-764.2005

[37] Diaz-Gonzalez, R., Kuhlmann, F.M., Galan-Rodriguez, C., da Silva, L.M., Saldivia, M., Karver, C.E., Rodriguez, A., Beverley, S.M., Navarro, M. and Pollastri, M.P. (2011) The susceptibility of trypanosomatid pathogens to PI3/ mTOR kinase inhibitors affords a new opportunity for drug repurposing. PLoS Neglected Tropical Diseases, 5, e1297. doi:10.1371/journal.pntd.0001297

[38] Marschall, A.L.J., Frenzel, A., Schirrmann, T., Schüngel, M. and Dubel, S. (2011) Targeting antibodies to the cytoplasm. $m A b s, 3,3-16$. doi: 10.4161/mabs.3.1.14110

[39] Gomez, E.B., Santori, M.I., Laria, S., Engel, J.C., Swindle, J., Eisen, H., Szankasi, P. and Tellez-Inon, M.T. (2001) Characterization of the Trypanosoma cruzi Cdc2prelated protein kinase 1 and identification of three novel associating cyclins. Molecular Biochemical Parasitology, 113, 97-108. doi:10.1016/S0166-6851(00)00382-0

[40] Santori, M.I., Laria, S., Gomez, E.B., Espinosa, I., Galanti, N. and Tellez-Inon, M.T. (2002) Evidence for CRK3 participation in the cell division cycle of Trypanosoma cruzi. Molecular and Biochemical Parasitology, 121, 225-232. doi:10.1016/S0166-6851(02)00039-7

[41] Potenza, M., Schenkman, S., Laverrière, M. and TellezIñón, M.T. (2012) Functional characterization of TcCYC2 cyclin from Trypanosoma cruzi. Experimental Parasitology, 132, 537-545. doi:10.1016/j.exppara.2012.09.002 